\title{
Soluble complement receptor type 1 (CD35) in bronchoalveolar lavage of inflammatory lung diseases
}

\author{
J. Hamacher*, S. Sadallah**, J.A. Schifferli**, J. Villard*, L.P. Nicod*
}

Soluble complement receptor type 1 (CD35) in bronchoalveolar lavage of inflammatory lung diseases. J. Hamacher, S. Sadallah, J.A. Schifferli, J. Villard, L.P. Nicod. CERS Journals Ltd 1998.

ABSTRACT: Complement receptor type 1 (CR1) $(\mathrm{CD35}$; $\mathrm{C} 3 \mathrm{~b} / \mathrm{C} 4 \mathrm{~b}$ receptor) is a transmembrane protein of many haematopoietic cells. Once cleaved, soluble complement receptor type 1 (sCR1) exerts opposite effects as a powerful inhibitor of complement. This study addressed both the question of whether SCR1 was found in bronchoalveolar lavage (BAL) of normals and patients with various inflammatory disease, and its possible origin.

In this retrospective study covering specimen and clinical data of $\mathbf{1 2 4}$ patients with acute and chronic inflammatory lung pathologies, BAL supernatants were analysed by enzyme-linked immunosorbent assay technique for SCR1. Correlations were made between the SCR1 levels obtained and the constituents of BAL. Human alveolar macrophages were cultivated in order to determine their secretory capacity of SCR1.

Alveolar macrophages from normal subjects were shown to release SCR1 in vitro. In addition, sCR1 was present in BAL of normal controls and was significantly increased in acute inflammatory lung diseases such as acute respiratory distress syndrome (ARDS), bacterial and Pneumocystis carinii pneumonia, as well as in chronic inflammatory diseases such as interstitial lung fibrosis and sarcoidosis. In BAL of ARDS, bacterial, and $P$. carinii pneumonia, there was a good correlation between sCR1 and the absolute neutrophil counts. In sarcoidosis, a correlation was found with BAL lymphocyte counts. Serum SCR1 was not increased in patients compared to controls.

Soluble complement receptor type 1 (sCR1) is found in the bronchoalveolar lavage in health as well as in acute and chronic inflammatory disease. Alveolar macrophages are capable of releasing $\mathrm{SCR} 1$ in vitro and may be the main physiological source of SCR1 in the alveoli. The good correlation between SCR1 and the absolute neutrophil or lymphocyte numbers in bronchoalveolar lavage of inflammatory diseases suggests a predominant role of leucocytes for the release of SCR1 in such conditions. The release of this inhibitor of complement may be crucial to control and reduce complement activation and thus prevent lung injury.

Eur Respir J 1998; 11: 112-119.
*Pulmonary Division, Hôpital Cantonal Universitaire, Geneva, and **Clinic of Medicine B, University Clinics, Cantonal Hospital, Basel, Switzerland.

Correspondence: L.P. Nicod

Pulmonary Division

Hôpital Cantonal Universitaire

CH-1211 Geneva 14

Switzerland

Fax: 0041227002672

Keywords: Acute respiratory distress syndrome

bronchoalveolar lavage

complement

complement receptor type 1

inflammatory lung diseases

lung

Received: October 301996

Accepted after revision September 51997

This study was supported by the Swiss National Research Fund, Nos. 32-32367.91 and 32-40844.94 and by the "Association Vaud-Genève", project No. 19
Complement receptor type 1 (CR1; CD35, C3b/C4b receptor) is a transmembrane glycoprotein found on erythrocytes and most white blood cells [1, 2]. For polymorphonuclear leucocytes (PMNs) and monocytes, the expression of CR1 (5,000-40,000 receptors.cell $\left.{ }^{-1}\right)$ depends on the cellular activation state: it is enhanced on PMNs after activation by agents such as formyl peptides, C5a, leukotriene B4, or tumour necrosis factor (TNF) [3]. On phagocytes, CR1 is mainly involved in the initial binding of particles coated with activated C3 (C3b), which are subsequently ingested [4]. In addition, CR1 serves as a cofactor for the degradation and inactivation of $\mathrm{C} 3 \mathrm{~b}$ by factor I [5]. Thus, CR1 is not only a cellular receptor, but also a potent inhibitor of both the classical and alternative pathway of complement activation. The suppression of alternative and classical pathway activation in whole serum at nanomolar concentrations led to the conclusion that sCR 1 is more than 100 fold more effective than other soluble comple- ment regulatory proteins, e.g. factor $\mathrm{H}$, the physiological cofactor for the inactivation of C3b in plasma $[4,6]$.

In vitro-activated PMNs shed a soluble form of $\mathrm{CR} 1$ (sCR1) which corresponds to the extracellular portion of the molecule [6]. An identical soluble CR1 is found in serum $[7,8]$. In vivo sCR1 was detected in the serum of severe combined immunodeficiency (SCID) mice populated with human peripheral blood leucocytes, indicating that the serum sCR1 derives from leucocytes [7].

Activation of the complement system is intended to protect our body from invading micro-organisms and other insults, but also has the potential to lyse our own cells [5]. Therefore, cells are protected from complementinduced cell lysis by a family of cell-membrane complement regulatory glycoproteins that down-regulate activation of homologous complement on their cell surface [5]. They include membrane cofactor protein (MCP; CD46), decay-accelerating factor (DAF; CD55), CD59 and CR1 
(CD35). While MCP and DAF prevent activation of the classic and alternative complement pathways, CD59 prevents formation of complement membrane-attack complexes on the surface of host cells [5]. MCP, DAF and CD59 are found in the whole human respiratory tract epithelium from nose to alveoli, and are even increased in inflamed tissue. CR1 has not been visualized on cells of the respiratory tract [9].

The present study was undertaken to investigate the presence and origin of sCR1 in culture supernatant of alveolar macrophages which are known to express CR1 on their surface [10], in bronchoalveolar lavages (BALs) of normals and patients with inflammatory lung diseases.

\section{Materials and methods}

\section{Subjects}

One hundred and twenty four patients undergoing routine bronchoscopy were included in this retrospective study. They consisted of a control group of 17 patients who were investigated by bronchoscopy for persistent cough or for a pulmonary nodule, of 31 patients with untreated sarcoidosis, and of 27 patients with interstitial lung fibrosis (classified as idiopathic lung fibrosis in 24 patients, and associated with a lymphocytic alveolitis and an anti JO-1 autoantibody in three cases). Fifteen patients were investigated with adult respiratory distress syndrome (ARDS) defined by: 1) acute onset of respiratory failure; 2) rapid appearance of bilateral alveolar infiltrates on chest radiograph; 3$)$ severe hypoxaemia with arterial oxygen tension $\left(\mathrm{Pa}, \mathrm{O}_{2}\right) /$ fractional concentration of oxygen in inspired gas $\left(F \mathrm{I}, \mathrm{O}_{2}\right)$ ratio $<120$; and 4$)$ pulmonary wedge capillary pressure $<15 \mathrm{mmHg}$. The last two groups consisted of 24 patients with Pneumocystis carinii pneumonia (23 human immunodeficiency virus (HIV)-infected and one cardiac transplant patient without HIV infection) and of 10 patients with bacterial pneumonia defined as the presence of a new infiltrate on chest radiograph with fever and purulent respiratory secretions, in addition to a positive culture ( $\breve{S} 10^{4}$ colony-forming units $(\mathrm{cfu}) \cdot \mathrm{mL}^{-1}$ in eight patients) obtained in the BAL, or a clinical and radiographic response to antibacterial antibiotics.

\section{Bronchoalveolar lavage}

Samples were collected according to published methods $[11,12]$. Briefly, a fibreoptic bronchoscope was wedged into the segmental bronchus of one lobe and three to four aliquots of $50 \mathrm{~mL}$ sterile isotonic saline were instilled and recovered by gentle hand suction. The BAL fluid was pooled and processed within $1 \mathrm{~h}$. After centrifugation $(800 \times \mathrm{g}, 10 \mathrm{~min})$, aliquots of the supernatant were stored at $-20^{\circ} \mathrm{C}$. Cell counts were determined in a Neubauer chamber. Differentials were made after cytocentrifugation on slides with May-Gruenwald-Giemsa colouration. Cell viability was assessed by Trypan blue exclusion.

\section{Enzyme-linked immunosorbent assay (ELISA) for sCRI}

For sCR1 in bronchoalveolar lavage fluid (BALF) and in serum, a sensitive ELISA sandwich assay using two
anti-CR1 monoclonal antibodies (MAbs) that recognize different epitopes of CR1 was used as previously described [7], using an Amersham biotinylation kit (Amersham International, Buckinghamshire, UK). Polystyrene microwell plates (Nunc Maxisorp immunoplates, GIBCO BRL, Basel, Switzerland) were coated with $100 \mu \mathrm{L}(0.3 \mu \mathrm{g}$. well $^{-1}$ ) in phosphate-buffered saline (PBS), $\mathrm{pH}$ 7.9) of purified 3D9 MAb and left overnight at room temperature. The plates were washed four times with PBS-Tween $0.05 \%$, and unbound sites were saturated with $2 \%$ bovine serum albumin (BSA)-PBS-Tween for $1 \mathrm{~h}$ at $37^{\circ} \mathrm{C}$. One hundred microlitres of the samples diluted in PBS-Tween were added, and the plates were incubated overnight at $4^{\circ} \mathrm{C}$. The plates were then washed four times and subsequently incubated with $100 \mu \mathrm{L}$ of biotinylated J3D3 MAb diluted at $1 / 3000$ (stock concentration: $0.5 \mathrm{mg} \cdot \mathrm{mL}^{-1}$ ) for 3 $\mathrm{h}$ at $37^{\circ} \mathrm{C}$. After washing the plates, $100 \mu \mathrm{L}$ of peroxidaseconjugated Streptavidin (Jackson Immuno Research Labs, Inc., West Grove, PA, USA) diluted at 1/2,000 was added to each well and incubation continued for $1 \mathrm{~h}$ at $37^{\circ} \mathrm{C}$. After washing, $100 \mu \mathrm{L}$ of substrate at a concentration of $0.4 \mathrm{mg} \cdot \mathrm{mL}^{-1}$ (orthophenyldiamine, in $50 \mathrm{~mL}$ citrate-phosphate buffer, $\mathrm{pH} 5$, with $20 \mu \mathrm{L}$ of $\mathrm{H}_{2} \mathrm{O}_{2}$ ) was added to each well. The reaction was stopped after 10 min with $\mathrm{H}_{2} \mathrm{SO}_{4}$, and absorbance was measured with a microplate reader (MR 600, Dynatech, 8423 Embrach, Switzerland) at 492 $\mathrm{nm})$. The lower limit of detection in BALF was 0.02 $\mathrm{ng} \cdot \mathrm{mL}^{-1}$. A standard of recombinant soluble CR1 was used (a kind gift of SmithKline Beecham Pharmaceuticals, King of Prussia, USA).

\section{Stability testing of $s C R 1$ in BALF supernatant}

Immediately after BAL of two patients, the fluid was aliquoted and protease inhibitors (1 $\mathrm{mM}$ phenylmethylsulphonyl fluoride (PMSF), $10 \mathrm{mM}$ ethylenediamine tetraacetic acid (EDTA), and $0.5 \mathrm{mM}$ di-isopropylfluorophosphate (DFP)) were added to one aliquot, another receiving the same volume of saline $0.9 \%$ and being left at room temperature during 0,10 and $100 \mathrm{~h}$ until measurement of sCR1 by ELISA. Two other BALF supernatant aliquots were exposed to room temperature for 0,24 and $48 \mathrm{~h}$ and to $37^{\circ} \mathrm{C}$ for $12 \mathrm{~h}$ in order to determine stability at that temperature in BALF.

sCR1 measurement in purified human alveolar macrophages (AMs) supernatant with and without simulation by lipopolysaccharide (LPS)

AMs were recovered by ex vivo lavage of surgical lung specimens with $0.9 \% \mathrm{NaCl}$. The aspirated cell population averaged $88 \%$ macrophages, $10 \%$ lymphocytes and $2 \%$ PMNs as assessed by May-Gruenwald-Giemsa slides. The cells were washed three times with PBS, and $1 \times 10^{6}$ cells. $\mathrm{mL}^{-1}$ were adhered for $60 \mathrm{~min}$ in RPMI 1640 (Kibbutz Bit Hae Mek, Israel) supplemented with $10 \%$ heat-inactivated foetal calf serum, penicillin $50 \mathrm{U} \cdot \mathrm{mL}^{-1}$, streptomycin 50 $\mu \mathrm{g} \cdot \mathrm{mL}^{-1}$, and glutamine $1 \%$ (all from GIBCO, Paisley, UK). The dishes were rinsed three times in order to remove all nonadherent cells. The adhered AMs were then cultured at $37^{\circ} \mathrm{C}$ with $5 \% \mathrm{CO}_{2}$ in the presence or absence of LPS ( $1 \mu \mathrm{g} \cdot \mathrm{mL}^{-1}$ Escherichia coli O55;B5, Difco laboratories, Detroit, MI, USA) for time courses extended to 48 h. 
ELISA for free and protease inhibitor complexed PMN elastase

BALF concentration of free PMN elastase and PMN elastase complexed with protease inhibitor (abbreviated as "PMN elastase") was measured by sandwich ELISA (PMN ELASTASE® Kit, Merck Immunoassay, Darmstadt, Germany), with a lower limit of detection of $0.33 \mu \mathrm{g} \cdot \mathrm{mL}^{-1}$. Sample dilutions ranging 1:5 to 1:500 were necessary for the BALF fluid supernatants studied.

\section{Protein assay}

Total protein in BALF was measured using Biuret technique based on the absorbance of Coomassie Blue to proteins, as described previously [13].

Correlation of results of the $\mathrm{P}$. carinii pneumonia group with the alveolar-arterial oxygen difference $\left(\mathrm{PA}-a, \mathrm{O}_{2}\right)$

The alveolar-arterial oxygen difference was calculated by the simplified formula:

$$
P \mathrm{~A}-\mathrm{a}, \mathrm{O}_{2}(\mathrm{kPa})=19.5-1.2 \times \mathrm{PCO}_{2}-\mathrm{PO}_{2}
$$

where $\mathrm{PCO}_{2}$ is partial pressure of carbon dioxide and $\mathrm{PO}_{2}$ is partial pressure of oxygen.

\section{Statistical analysis}

Data were analysed using the SYSTAT for Windows ${ }^{\circledR}$ software package (SYSTAT Inc., Evanston, IL, USA), using Pearson correlation for the relationship analyses between sCR1, cytokine, protein, and "PMN elastase" levels and cell count. Probabilities were adjusted by the Bonferroni method for multiple comparisons of variables. Due to not normally distributed variables, the Kruskal-Wallis test was used for the analysis of significant differences of a variable between three or more independent groups; if significant, Mann-Whitney test was used when differences between two groups were analysed. The Wilcoxon matched-pairs signed ranks test was used for matched pairs of variables. In all tests, a p-value ð0.05 was considered as significant. All descriptive statistical results were expressed as mean (SD).

\section{Results}

\section{sCRl production by $A M s$ in vitro}

Purified AMs stimulated by the culture conditions alone released high concentrations of SCR1 into culture supernatant. This release reached $0.14 \pm 0.12 \mathrm{ng} \cdot \mathrm{mL}^{-1} \mathrm{sCR} 1$ (mean $\pm \mathrm{SD}$ ) after $24 \mathrm{~h}$ and $0.25 \pm 0.24 \mathrm{ng} \cdot \mathrm{mL}^{-1}$ after $48 \mathrm{~h}$ (fig. 1). This release was not increased by the presence of LPS ( $\mathrm{p}=1.0$; Wilcoxon test). The viability of AMs after 48 $\mathrm{h}$ was always $>80 \%$ determined by Trypan blue exclusion.

\section{sCR1 in BALF of various lung disease}

sCR1 was present in BALF supernatant of all subjects tested. Differences between the diagnostic groups were significant (Kruskal-Wallis test; $\mathrm{p}<0.0005$ ). Compared to

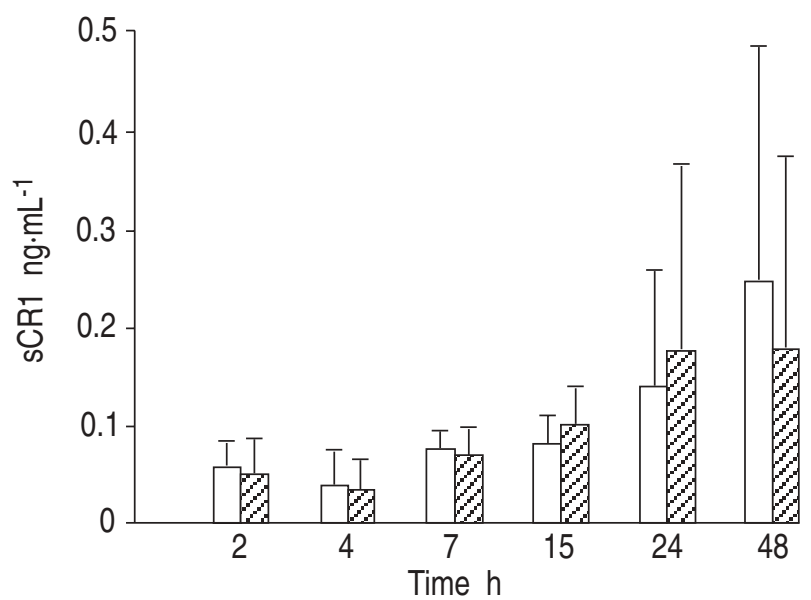

Fig. 1. - Release of soluble complement receptor type 1 (sCR1) by human alveolar macrophages in culture in the presence or absence of lipopolysaccharide (LPS). Results are expressed as mean \pm SD at different time points. No differences were found between the two conditions tested by Wilcoxon test ( $\mathrm{p}=0.10)$. $\square$ : without LPS; $G$ : with LPS.

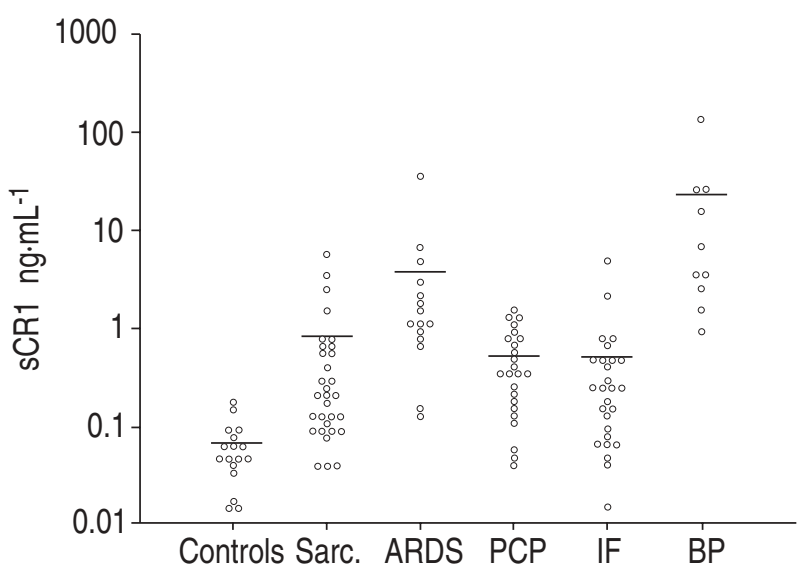

Fig. 2. - Levels of sCR1 in bronchoalveolar lavage. sCR1 levels differ significantly between the groups ( $\mathrm{p}<0.0005$, Kruskal-Wallis test). Compared to controls, sCR1 is significantly increased in every disease group $(\mathrm{p}<0.001$ between controls and every disease group, Mann-Whitney test). A significant difference between the ARDS and the bacterial pneumonia groups is present $(\mathrm{p}=0.015)$. The differences between the sarcoidosis, PCP, and idiopathic pulmonary fibrosis group are nonsignificant. Bars represent mean values. SCR1: soluble complement receptor type 1; Sarc.: sarcoidosis; ARDS: acute respiratory distress syndrome; PCP: Pneumocystis carinii pneumonia; IF: interstitial fibrosis; BP: bacterial pneumonia.

controls, sCR1 levels were significantly increased in BALF of all acute and chronic inflammatory diseases tested $(\mathrm{p}<$ 0.005 , Mann-Whitney test), with highest levels in bacterial pneumonia, followed by the ARDS group (fig. 2). In bacterial pneumonia, the mean BAL sCR1 content is about 300 times higher and in ARDS 60 times higher than in controls. In interstitial lung fibrosis, sarcoidosis, and $P$. carinii pneumonia it is about eight, 12 and seven times higher compared to the same controls.

\section{sCR1 stability in BALF}

Aliquots of BAL supernatants were stored at room temperature for $100 \mathrm{~h}$ or at $37^{\circ} \mathrm{C}$ for $12 \mathrm{~h}$ with presence or absence of protease inhibitors. With and without enzyme 
Table 1. - Cell count distribution "PMN elastase" and protein content in bronchoalveolar lavage fluid or supernatant of the various subjects studied

\begin{tabular}{lcccccccc}
\hline Diagnosis & $\begin{array}{c}\text { Subjects } \\
\mathrm{n}\end{array}$ & $\begin{array}{c}\mathrm{sCR} 1 \\
\mathrm{ng} \cdot \mathrm{mL}^{-1}\end{array}$ & $\begin{array}{c}\text { Cell count } \\
\times 10^{4} \cdot \mathrm{mL}^{-1}\end{array}$ & $\begin{array}{c}\text { PMN } \\
\%\end{array}$ & $\begin{array}{c}\text { Macrophages } \\
\%\end{array}$ & $\begin{array}{c}\text { Lymphocytes } \\
\%\end{array}$ & $\begin{array}{c}\text { "PMN elastase" } \\
\mu \mathrm{g} \cdot \mathrm{mL}^{-1}\end{array}$ & $\begin{array}{c}\text { Protein } \\
\mu \mathrm{g} \cdot \mathrm{mL}^{-1}\end{array}$ \\
\hline Controls & 17 & $0.07 \pm 0.04$ & $19.5 \pm 11.2$ & $1.6 \pm 1.0$ & $85.5 \pm 8.1$ & $12.0 \pm 8.0$ & $2.6 \pm 2.4$ & $46 \pm 23$ \\
Sarcoidosis & 31 & $0.69 \pm 1.28$ & $41.1 \pm 25.3^{\ddagger}$ & $6.2 \pm 9.7$ & $50.4 \pm 20.9$ & $41.5 \pm 21.7$ & $10.8 \pm 11.1^{*}$ & $430 \pm 733^{\ddagger}$ \\
IF & 27 & $0.55 \pm 1.04$ & $47.2 \pm 51.1^{*}$ & $18.4 \pm 23.8^{\ddagger}$ & $51.1 \pm 24.4$ & $25.4 \pm 22.3$ & $28.5 \pm 37.6^{\ddagger}$ & $212 \pm 332^{\ddagger}$ \\
ARDS & 15 & $4.20 \pm 2.4^{\ddagger}$ & $44.5 \pm 11.5$ & $64.3 \pm 29.8^{\ddagger}$ & $29.0 \pm 23.7$ & $5.3 \pm 4.6^{*}$ & $91.1 \pm 60.8^{\ddagger}$ & $1101 \pm 1974$ \\
PCP & 24 & $0.54 \pm 0.46$ & $29.1 \pm 15.7^{*}$ & $18.9 \pm 24.8^{\ddagger}$ & $55.3 \pm 23.1^{*}$ & $23.5 \pm 15.3^{*}$ & $16.2 \pm 14.7$ & $233 \pm 225$ \\
BP & 10 & $21.30 \pm 38.00^{\ddagger}$ & $206.0 \pm 230.0^{\ddagger}$ & $84.5 \pm 12.1^{\ddagger}$ & $9.8 \pm 7.3^{\ddagger}$ & $5.1 \pm 4.7^{*}$ & $565.0 \pm 626.0^{\ddagger}$ & $776 \pm 949$ \\
\hline
\end{tabular}

Values are means \pm SD. All parameters showed significant differences concerning diagnostic groups (Kruskal-Wallis test, $\mathrm{p}<0.0005$ ). $*$ : $\mathrm{p}<0.05$; $: \mathrm{p}<0.005$, versus controls (Mann-Whitney test). "PMN elastase": free protease inhibitor complexed polymorphonuclear leucocyte elastase. For further definitions see legend to figure 2.

inhibitor, the aliquots remained stable. The difference of sCR1 was always $ð 10 \%$, suggesting that sCR1 is stable in the BAL and is not rapidly degraded by enzymes which might be present (data not shown).

sCR1, various cells, "PMN elastase", and protein in BAL

The cell count and distribution found in these various pathologies are given as well as the content of protein and the "PMN elastase" (table 1). All categories (cell count; PMN percentage; macrophages percentage; lymphocytes percentage; "PMN elastase"; protein) analysed in table 1 showed significant differences concerning diagnostic groups (Kruskal-Wallis test, $\mathrm{p}<0.0005$ ). As expected, bacterial pneumonia and ARDS showed the highest PMN numbers, "PMN elastase", and protein levels in BAL, whereas in interstitial lung fibrosis, sarcoidosis and $P$. carinii pneumonia the "PMN elastase" and protein levels found in BAL are of intermediate amount and quite similar.

sCRI correlations with various cells and cell viability in $B A L$ in the pooled data

A significant correlation was found between sCR1 and absolute PMN count $(\mathrm{r}=0.89, \mathrm{p}<0.005 ; \mathrm{n}=124$; Pearson test, probability corrected for five comparisons (Bonferroni's inequality correction)) in the pooled data, suggesting a close relationship between sCR1 and PMN count in BAL.

No correlations were found between $\mathrm{sCR} 1$ and macrophage counts in the pooled data $(\mathrm{r}=0.01 ; \mathrm{p}=1.0 ; \mathrm{n}=$ 124; Pearson test, probability corrected for five comparisons (Bonferroni's inequality correction)). The same was true for the lymphocytes $(\mathrm{r}=0.4, \mathrm{p}=1.0 ; \mathrm{n}=124$; Pearson test, probability corrected for five comparisons (Bonferroni's inequality correction)).

There was also no correlation between cell viability (trypan exclusion) and $\mathrm{sCR} 1$ in BAL $(\mathrm{r}=0.04 ; \mathrm{p}=1 ; \mathrm{n}=124$, Pearson test, probability corrected for five comparisons (Bonferroni's inequality correction)).

\section{sCR1 correlations with BAL cells and "PMN elastase" in the different diagnostic groups}

The different diagnostic groups were analysed for correlations with BAL sCR1 levels according to their cell prevalence in BAL. "PMN elastase" correlations were only performed where PMNs were predominant.
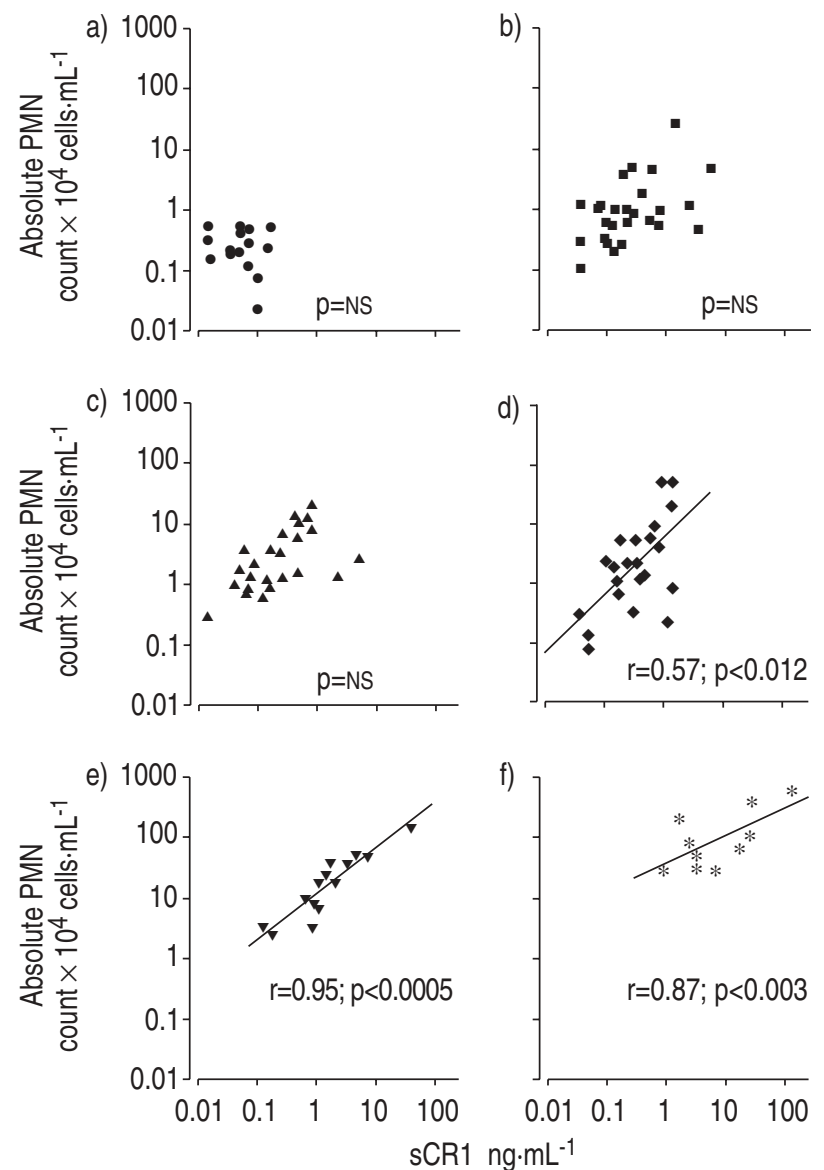

Fig. 3. - Relationship between the absolute BAL PMN count and the BAL sCR1 level. Correlations between the absolute BAL PMN count and the BAL sCR1 level are found in both pneumonia groups and in acute respiratory distress syndrome (ARDS) by Bonferroni-adjusted Pearson test. a) controls; b) sarcoidosis; c) interstitial fibrosis; d) Pneumocystis carinii pneumonia; e) ARDS; f) bacterial pneumonia; Ns: nonsignificant; PMN: polymorphonuclear leucocyte; BAL: bronchoalveolar lavage; sCR1: soluble complement receptor type 1 .

As summarized in figure 3 , a correlation was found between BAL SCR1 and absolute PMN count in bacterial and Pneumocystis carinii pneumonia as well as in ARDS.

In the control group, no correlation was found between sCR1 and absolute macrophage, lymphocyte, or PMN cell count $(\mathrm{r}=-0.36, \mathrm{p}=1 ; \mathrm{r}=0.002, \mathrm{p}=1$; and $\mathrm{r}=-0.07, \mathrm{p}=1$, respectively; Pearson test, probability corrected for four comparisons (Bonferroni's inequality correction); one correlation see later). Due to the missing correlations of 


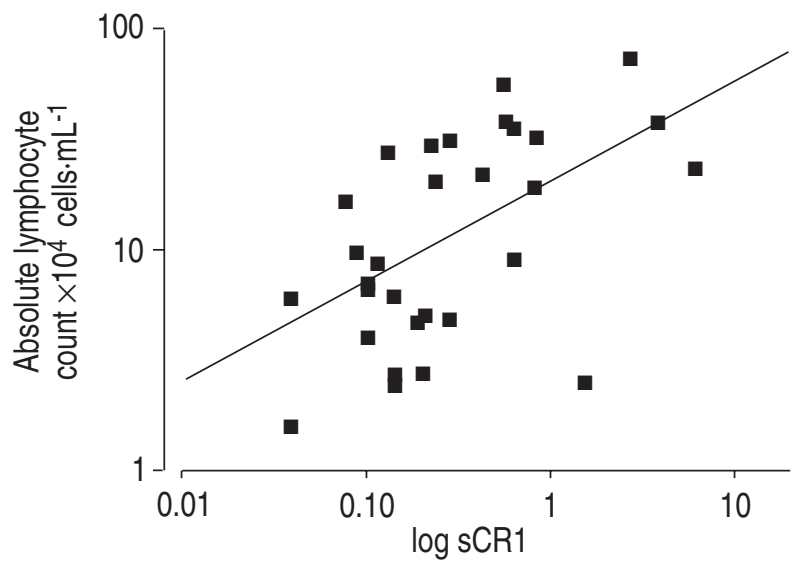

Fig. 4. - Relationship between the absolute BAL lymphocyte count and the BAL sCR1 level. There is a significant correlation in the sarcoidosis group by Bonferroni-adjusted Pearson test $(\mathrm{r}=0.41, \mathrm{p}<0.044)$. sCR1: soluble complement receptor type 1; BAL: bronchoalveolar lavage.

sCR1 with macrophages in the overall data as well as in controls, which is the group with highest macrophages percentage, there were no more correlations analysed between those two parameters.

In the sarcoidosis group, a significant correlation of sCR1 was found with absolute lymphocyte count ( $\mathrm{r}=0.41$, $\mathrm{p}<0.044$; Pearson test, probability corrected for two comparisons (Bonferroni's inequality correction) (fig. 4).

In the interstitial lung fibrosis group, sCR1 did not correlate with the absolute PMN or the absolute lymphocyte count ( $\mathrm{r}=0.06, \mathrm{p}=1$; and $\mathrm{r}=0.24, \mathrm{p}<0.67$, respectively; Pearson test, probabilities corrected for three comparisons (Bonferroni's inequality correction)).

In $P$. carinii pneumonia, sCR1 correlated with the absolute PMN count and with "PMN elastase", $(\mathrm{r}=0.57, \mathrm{p}<$ 0.012 ; and $\mathrm{r}=0.81, \mathrm{p}<0.0005$, respectively, Pearson test, probabilities corrected for four comparisons (Bonferroni's inequality correction) (fig. 5)).

In the ARDS group, sCR1 correlated with the absolute PMN count and with the "PMN elastase", but not with protein $(\mathrm{r}=0.95, \mathrm{p}<0.0005$; and $\mathrm{r}=0.60, \mathrm{p}<0.037$, respectively; Pearson test, probabilities corrected for three comparisons (Bonferroni's inequality correction)).

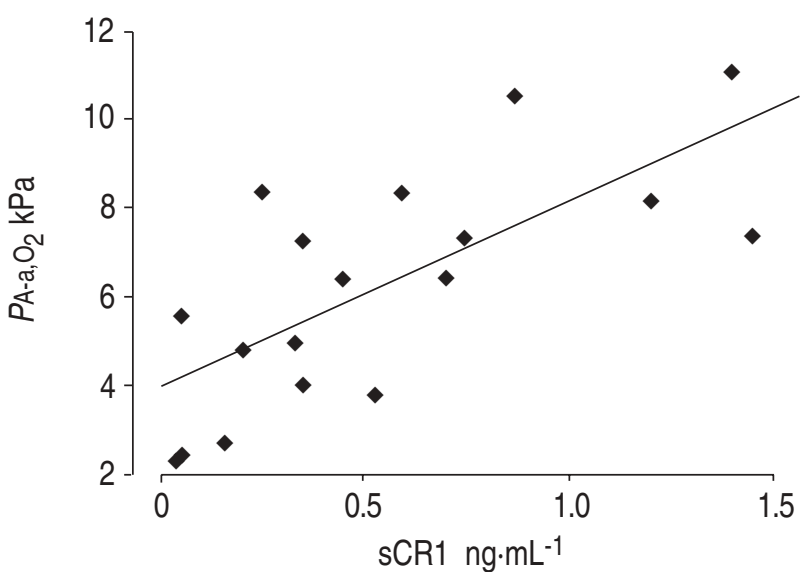

Fig. 5. - Relationship between the alveolar-arterial oxygen difference $\left(P \mathrm{~A}-\mathrm{a}, \mathrm{O}_{2}\right)$ and the BAL sCR1 levels in Pneumocystis carinii pneumonia. A linear correlation is found by Bonferroni-adjusted Pearson test $(n=18$; $\mathrm{r}=0.71, \mathrm{p}<0.004)$. For definitions, see legend to figure 4.
In the bacterial pneumonia group, sCR1 correlated with the absolute PMN count, whereas the correlation with "PMN elastase" was only nearly significant $(r=0.87, \mathrm{p}<0.003$; and $\mathrm{r}=0.74$, p $<0.067$, respectively; Pearson test, probabilities corrected for three comparisons (Bonferroni's inequality correction)).

sCRl correlations with protein in BAL of various lung diseases

The correlations of $\mathrm{sCR} 1$ with protein in BAL were investigated in the different diagnostic groups in order to examine whether or not a plasma leakage was the main source of sCR1 in BAL. The only significant correlation found between the two parameters was in the bacterial pneumonia group $(\mathrm{r}=0.97, \mathrm{p}<0.005$; Bonferroni-corrected Pearson test). In ARDS, a disease classically associated with plasma leakage into the alveoli, no correlation was found between BAL sCR1 and BAL protein $(\mathrm{r}=0.10, \mathrm{p}=1$; Bonferroni-corrected Pearson test). The same was true in the $P$. carinii, sarcoidosis, interstitial fibrosis, and the control group ( $r=0.32, p<0.89 ; \mathrm{r}=0.20, \mathrm{p}<0.90, \mathrm{r}=0.39$, $\mathrm{p}<0.15$; and $\mathrm{r}=0.13, \mathrm{p}=1$, respectively; Bonferroni-corrected Pearson tests).

\section{sCR1 levels in serum compared to BALF}

The normal level of sCR1 in serum is $31.4 \pm 7.8 \mathrm{ng} \cdot \mathrm{mL}^{-1}$ (mean \pm sD; $n=31$ ) $[7,14]$. The concentrations of sCR1 in available sera were studied in most pathological groups and were not shown to be significantly changed compared to normal controls (table 2). The mean serum level of all samples studied $(\mathrm{n}=29)$ was $40.0 \pm 25.7 \mathrm{ng} \cdot \mathrm{mL}^{-1}$ with higher mean values in pathological states such as sarcoidosis. However, the values are dispersed in each group and more samples would be needed to infirm or confirm a real difference compared to normal levels.

In the 29 paired samples of patients, there was no correlation between the serum sCR1 and BAL sCR1 ( $\mathrm{r}=0.10$, $\mathrm{p}=1 ; \mathrm{n}=29$; Bonferroni-corrected Pearson test), suggesting that BAL sCR1 originates from the local cells.

The correlation between SCR1 present in BAL and the protein content was determined. A correlation was found only in bacterial pneumonia (see above), implying that in this condition some of the sCR 1 concentration found in BAL might be due to exudation of plasma through vascular leaks. However, while the protein content of the BAL is 100 fold lower than the normal concentration of the proteins in plasma, the sCR1 in BAL reached $20 \%$ of the plasma values despite the high molecular weight of sCR1. This requires a local production of sCR1 in the alveoli, e.g. from leucocytes.

If a serum protein content of $50 \mathrm{~g} \cdot \mathrm{L}^{-1}$ is assumed, the relation of $\mathrm{sCR} 1 /$ protein in BAL divided by $\mathrm{sCR} 1 /$ protein in serum (the "sCR1 concentration ratio") ranges 0.5-73. This means that, when referred to the protein concentrations in BAL or serum, the concentration of sCR1 in BAL is enhanced compared to sCR1 in serum in all groups. The mean enhancement varies between 1.6 and 15.5 (table 2), e.g. in the two patients from the bacterial pneumonia group this "sCR1 concentration ratio" was calculated to be 14 and 16. the "sCR1 concentration ratios" of more than 
Table 2. - sCR1 in paired samples of BAL and serum in different disease groups

\begin{tabular}{lccccc}
\hline Group & $\begin{array}{c}\text { Subjects } \\
\text { tested } \\
\mathrm{n}\end{array}$ & $\begin{array}{c}\mathrm{BAL} \mathrm{sCR} 1 \\
\mathrm{ng} \cdot \mathrm{mL}^{-1}\end{array}$ & $\begin{array}{c}\text { serum sCR1 } \\
\mathrm{ng} \cdot \mathrm{mL}^{-1}\end{array}$ & $\begin{array}{c}\text { sCR1 BAL/ } \\
\text { serum } \\
\text { ratio }\end{array}$ & $\begin{array}{c}\text { sCR1 BAL/BAL protein } \\
\div \\
\text { sCR1 serum/serum protein }\end{array}$ \\
\hline Controls & 2 & $0.04 \pm 0.03$ & $50.8 \pm 3.1$ & $0.01 \pm 0.01$ & $1.6 \pm 1.5$ \\
Sarcoidosis & 4 & $0.46 \pm 0.24$ & $67.5 \pm 26.0$ & $0.06 \pm 0.03$ & $2.6 \pm 2.3$ \\
IF & 14 & $0.45 \pm 0.60$ & $39.5 \pm 26.1$ & $0.02 \pm 0.02$ & $9.2 \pm 19.0$ \\
ARDS & $0 *$ & $\mathrm{ND}$ & $\mathrm{ND}$ & $\mathrm{ND}$ & $\mathrm{ND}$ \\
PCP & 7 & $0.75 \pm 0.44$ & $21.0 \pm 12.2$ & $0.04 \pm 0.03$ & $6.0 \pm 3.7$ \\
BP & 2 & $9.80 \pm 9.20$ & $45.2 \pm 29.5$ & $0.20 \pm 0.08$ & $15.5 \pm 1.0$ \\
\hline
\end{tabular}

Values are means \pm SD. \#: assuming an amount of serum protein of $50 \mathrm{~g} \cdot \mathrm{L}^{-1}$ in each patient; *: no sera available; ND: not determined; BAL: bronchoalveolar lavage. For further definitions, see legend to figure 2.

10 fold in the two pneumonia patients and reaching in one patient more than 70 fold strongly suggest again that the sCR1 found in BAL is not only the result of serum leakage.

\section{sCRI and $\mathrm{P}$. carinii pneumonia severity}

In $P$. carinii pneumonia, a correlation was found between sCR1 and the worsening of the $P \mathrm{~A}-\mathrm{a}, \mathrm{O}_{2}$ measured in each case, as shown in figure 5.

\section{Discussion}

This study demonstrates significant amounts of sCR1 in BALFs of normal individuals. Higher amounts of sCR1 were found in BALFs of several inflammatory lung diseases. In vitro, AMs release sCR1. They might be a physiological source of the sCR1 found in BAL, whereas in conditions where PMNs predominate in the alveoli, the PMNs may be the most important producers. In these conditions, sCR1 correlated with the BAL neutrophil count as well as with "PMN elastase", underlining the potential role of the activated PMNs in the release of sCR1. The highest sCR1 levels in BAL were found in bacterial pneumonia, followed by ARDS. In sarcoidosis, interstitial lung fibrosis and $P$. carinii pneumonia, the BAL sCR1 levels were much lower, but still differed significantly from normal controls. The BAL levels of this most potent complement inhibitor seemed to be independent of the sCR1 blood levels and, in BAL of bacterial pneumonia patients, reached nearly the range of blood levels, favouring the hypothesis of local alveolar release of sCR1.

Complement is a proteolytic cascade system that interacts with cells and is present in blood plasma and other body fluids of all vertebrates. It induces and mediates an inflammatory response by producing peptides with chemotactic or anaphylactic activity and by interacting with specific cellular complement receptors [15], thereby enhancing the innate and specific immune responses [4]. The former is mediated by products of C3 and C5 activation that cause changes in vascular permeability $(\mathrm{C} 3 \mathrm{a}$, C5a), leucocyte adhesion, migration, the stimulation of cytokine synthesis such as interleukin- 6 by C5a $[15,16]$, and direct membrane damage (C5b-9) $[4,15]$.

PMNs play a key role in acute inflammatory diseases. Their recruitment at inflamed sites is followed by activation of these cells with release of proteolytic enzymes and complement proteins C3a and C5a $[15,16]$. The observation that a regulator of complement activation, i.e. $\mathrm{CR} 1$, is also released by PMNs is thus of great interest since this release will have an opposite effect by reducing further complement activation and shifting locally the balance in favour of complement inhibition [17].

Pneumocytes type II, AMs and fibroblasts synthesize and release several complement components [18-21]. Complement plays an important role in the defence against pulmonary infections, for the clearance of Streptococcus pneumoniae or Pseudomonas aeruginosa in models of bacterial pneumonia [22-24]. CR1 as well as the complement receptor and leucocyte adhesion molecule CR3 (CD11b/CD18; Mac-1) have been shown to be crucial for the phagocytosis of organisms such as Mycobacterium tuberculosis and Legionella pneumophila [25, 26].

sCR1 accelerates the decay of the C3/C5 convertase complexes and participates in the degradation of $\mathrm{C} 3 \mathrm{~b}$ and $\mathrm{C} 4 \mathrm{~b}[4,6]$. In-vivo studies in the rat have shown that sCR1 is able to reduce infarct size after induced myocardial ischaemia [6], local and remote tissue damage after intestinal ischaemia reperfusion [27], and tissue injury following intradermal injection of immune complexes [28]. sCR1 has been shown to attenuate the complement-mediated hyperacute rejection in animal models of xenograft $[29$, 30]. sCR1 protects against lung and dermal injury in different models of complement-dependent acute inflammatory injury [31]. sCR1 in plasma is thought to be released by leucocytes, probably similarly to selecting, with which it shares many structural features [7]. In vitro results show its release by monocytes, lymphocytes, and PMNs [7].

AMs, the predominant immune cells in the healthy individual's alveolar space and important immunoregulators $[10,32]$, are known to express CR1 on their surface [10]. Our data demonstrate the release of sCR1 by AMs in vitro. Being the predominant cell expressing CR1 in normal alveoli, AMs may be its major source in normal subjects. Other local sources such as alveolar or airway epithelial cells appear unlikely according to the findings of VARSANO et al. [9].

We found the highest sCR1 levels in BAL of bacterial pneumonia. The good correlation of sCR1 with neutrophil counts suggests that they might be the source of sCR1. The sCR1 found in the alveoli might protect the lung from tissue injury. The correlation found between the protein content of the alveoli and sCR1 in the alveoli may imply that some sCR1 comes from the vascular compartment and thus is not exclusively produced locally. However, despite a 100 fold lower protein content due to the dilution of the alveolar lining fluid during BAL procedure [33], its content of sCR1 is close to that measured in serum, which suggests a local production of sCR1 in this condition. However, our data do not allow to determine its 
biological effect, nor if a lack of sCR1 may favour tissue necrosis or lung abscesses.

In $P$. carinii pneumonia, the lowest $\mathrm{sCR} 1$ values of the investigated diseases are found. In this condition, activation of the complement system has been postulated with the augmented BAL C3 levels found [34]. Nevertheless, compared to bacterial pneumonia, the mean $\mathrm{sCR} 1$ value is 40 times lower. There is, however, a significant correlation in $P$. carinii pneumonia between sCR1 and BAL PMN counts. A significant correlation is also found between sCR1 and the patient's $P A-a, O_{2}$ as an index of severity of the disease. An inverse correlation between $P A-a, O_{2}$ and sCR1 was thus not found. Nevertheless, an imbalance between the activity of complement and its inhibitors in the most severe clinical manifestation cannot be ruled out as a factor increasing lung injury [35].

The second highest levels were found in ARDS, with a mean BAL sCR1 level five times lower than in bacterial pneumonia. As in $P$. carinii pneumonia, sCR1 correlates with both the PMN count and "PMN elastase" in BAL. In ARDS, complement is activated $[36,37]$, but not in a predictive way [38]. In a rat model of ARDS induced by LPS and platelet-activating factor, high dose of human SCR1 prevented lung oedema, alveolar neutrophilic infiltration, decreased BAL cell count and protein changes [39]. sCR1 also attenuated $\mathrm{C} 3$ and membrane attack complex deposition to lung vessels. It did not decrease lung myeloperoxidase activity, a marker of neutrophil infiltration in the lung interstitium [39], which is complement independent [40]. These experiments and our finding may justify pursuing the study of the potential protection that $\mathrm{sCR} 1$ could provide in ARDS.

There is also evidence of a role of complement in pulmonary sarcoidosis [34, 41]. Increases of C3a levels in BAL [34] and of complement synthesis by AMs have been observed [19, 42]. Compared to normal controls, PeTTERSEN et al. [43] found a higher expression of CR1 and CR3 and phagocytosis of AMs in patients with sarcoidosis stages I to III according to SILTzBACH [44]. In sarcoidosis, sCR1 correlated with the BAL lymphocyte count, suggesting a lymphocyte-dependent sCR1 production in this disease. These findings strengthen a role of complement in sarcoidosis that is independent of PMNs.

Our data do not elucidate the small amount of evidence of a pathogenic role of complement in interstitial lung fibrosis. Increased numbers of lung fibroblasts with highaffinity $\mathrm{Clq}$ receptors are found in fibrotic lung disease and may play a pathogenic role. Compared to fibroblasts with low affinity $\mathrm{C} 1 \mathrm{q}$ receptors they grow faster, synthesize more collagen in response to TGF- $\beta$ and are less inhibited by interferon $\gamma[45]$.

In conclusion, soluble complement receptor type 1 , a very potent complement inhibitor, can be found in the bronchoalveolar lavage in health as well as in acute and chronic inflammatory disease. This important physiological complement inhibitor found in the respiratory tract in soluble form, contrarily to the epithelium-bound complement regulatory proteins membrane cofactor protein, decay-accelerating factor and CD59 [9], may be important to prevent lung injury in several acute and chronic inflammations. The observation that soluble complement receptor type 1 could be measured in bronchoalveolar lavage with a monoclonal antibody known to recognise the $\mathrm{C} 3 \mathrm{~b} /$ $\mathrm{C} 4 \mathrm{~b}$ binding sites suggests that the molecule is functional
$[46,47]$. Whether this complement receptor type 1 release is sufficient to inhibit complement activation in vivo remains to be determined.

Acknowledgements: The authors thank F. Songeon for her expert technical assistance, N. Boehringer for her expert help and materials in the alveolar macrophage assays, J-D. Graf for the processing of the BAL, and S. Héritier for statistical advice.

\section{References}

1. Kazatchkine MD, Fearon DT. Deficiencies of human complement receptors type 1 (CR1, CD35) and type 2 (CR2, CD21). Immunodef Rev 1990; 2: 17-41.

2. Schifferli JA, Yin CN, Peters DK. The role of complement and its receptor in the elimination of immune complexes. New Engl J Med 1986; 315: 488-495.

3. Berger M, Wetzler E, Wallis RS. Tumor necrosis factor is the major monocyte product that increases complement receptor expression on mature human neutrophils. Blood 1988; 71: 151-158.

4. Fearon DT. Anti-inflammatory and immunosuppressive effects of recombinant soluble complement receptors. Clin Exp Immunol 1991; 86 (Suppl. 1): 43-46.

5. Lachmann PJ. The control of homologous lysis. Immunol Today 1991; 12: 312-315.

6. Weisman HF, Bartow T, Leppo MK, et al. In vivo inhibitor of complement suppressing post-ischemic myocardial inflammation and necrosis. Science 1990; 249: 146-152.

7. Pascual M, Duchosal MA, Steiger G, et al. Circulating soluble CR1 (CD35). Serum levels in diseases and evidence for its release by human leukocytes. J Immunol 1993; 151: 1702-1711.

8. Sadallah S, Giostra E, Mentha G, Schifferli JA. Increased levels of soluble complement receptor 1 in serum of patients with liver diseases. Hepatology 1996; 24: 118-122.

9. Varsano S, Frolkis I, Ophir D. Expression and distribution of cell-membrane complement regulatory glycoproteins along the human respiratory tract. Am J Respir Crit Care Med 1995; 152: 1087-1093.

10. Lohmann-Matthes ML, Steinmüller C, Franke-Ullmann G. Pulmonary macrophages. Eur Respir J 1994; 7: 16781689.

11. Reynolds HY. Bronchoalveolar lavage. Am Rev Respir Dis 1987; 135: 250-263.

12. Klech H, Pohl W. Technical recommendations and guidelines for bronchoalveolar lavage (BAL). Eur Respir $J$ 1989; 2: 561-585.

13. Bradford MM. A rapid and sensitive method for the quantification of microgram quantities of protein utilizing the principle of protein-dye binding. Annal Biochem 1976; 72: 248-254.

14. Yoon SH, Fearon DT. Characterization of a soluble form of the $\mathrm{C} 3 \mathrm{~b} / \mathrm{C} 4 \mathrm{~b}$ receptor $(\mathrm{CR} 1)$ in human plasma. $J$ Immunol 1985; 134: 3332-3338.

15. Tomlinson S. Complement defense mechanisms. Curr Opin Immunol 1993; 5: 83-89.

16. Morgan EL, Sanderson S, Scholz W, Noonan DJ, Weigle WO. Identification and characterization of the effector region within human $\mathrm{C5}$ a responsible for stimulation of IL-6 synthesis. J Immunol 1992; 148: 3937-3942.

17. Sadallah S, Schifferli JA, Pascual M. Proteolytic cleavage of leukocyte membrane proteins: lessons from CR1. Immunol Today 1996; 17: 345.

18. Scherzer HH, Kreutzer DL, Varani J, Desai U, Senior 
RM. Demonstration of the synthesis of the third and fifth components of complement by human macrophages. $\mathrm{Am}$ Rev Respir Dis 1980; 121 (Suppl.): 92.

19. Pettersen HB, Johnson E, Mollnes TE, Garred P, Hetland G, Osen SS. Synthesis of complement by alveolar macrophages from patients with sarcoidosis. Scand J Immunol 1990; 31: 15-23.

20. Rothman BL, Merrow M, Bamba M, Kennedy T, Kreutzer DL. Biosynthesis of the third and fifth complement components by isolated human lung cells. Am Rev Respir Dis 1989; 139: 212-220.

21. Strunk RC, Eidlen DM, Mason RJ. Pulmonary alveolar type II epithelial cells synthesize and secrete proteins of the classical and alternative complement pathways. J Clin Invest 1988; 81: 1419-1426.

22. Gross GN, Rehm SR, Pierce AK. The effect of complement depletion in lung clearance of bacteria. J Clin Invest 1978; 62: 373-378.

23. Toews GB, Pierce AK. The fifth component of complement is not required for the clearance of Staphylococcus aureus. Am Rev Respir Dis 1984; 129: 597-601.

24. Höpken UK, Lu B, Gerard NP, Gerard C. The C5a chemoattractant receptor mediates mucosal defence to infection. Nature 1996; 38: 886-889.

25. Schlesinger LS, Bellinger-Kawahara CG, Payne NR, Horwitz MA. Phagocytosis of mycobacterium tuberculosis is mediated by human monocyte complement receptors and complement component C3. J Immunol 1990; 144: 27712780.

26. Payne NR, Horwitz MA. Phagocytosis of legionella pneumophila is mediated by human complement receptors. $J$ Exp Med 1987; 166: 1377-1389.

27. Hill J, Lindsay TF, Oritz F, Yeh CG, Hechtman HB, Moore FD. Soluble complement receptor type 1 ameliorates the local and remote organ injury after intestinal ischemia-reperfusion in the rat. J Immunol 1992; 149: 1723-1728.

28. Yeh CG, Marsh HCJ, Carson GR, et al. Recombinant soluble human complement receptor type 1 inhibits inflammation in the reversed passive Arthus reaction in rats. $J$ Immunol 1991; 146: 250-256.

29. Pruitt SK, Baldwin WMI, Marsh HC, Lin SS, Yeh CG, Bollinger RR. The effect of soluble complement receptor type I on hyperacute xenograft rejection. Transplantation 1991; 52: 868-873.

30. Morgan BP. Complement regulatory molecules: application to therapy and transplantation. Immunol Today 1995; 16: 257-259.

31. Mulligan MS, Yeh CG, Rudolph AR, Ward PA. Protective effects of soluble CR1 in complement- and neutrophilmediated tissue damage. J Immunol 1992; 148: 14791485.

32. Bilyk N, Holt PG. Cytokine modulation of the immunosuppressive phenotype of pulmonary alveolar macrophage populations. Immunology 1995; 86: 231-237.
33. Kelly CA, Fenwick JD, Corris PA, Fleetwood A, Hendrick DJ, Walters EH. Fluid dynamics during bronchoalveolar lavage. Am Rev Respir Dis 1988; 138: 81-84.

34. van de Graaf EA, Jansen HM, Bakker MM, Alberts C, Eftinck Schattenkerk JKM, Out TA. ELISA of complement C3a in bronchoalveolar lavage fluid. J Immunol Methods 1992; 147: 241-250.

35. Walzer PF. Pathogenic mechanisms. In: Walzer PF, ed: Pneumocystis carinii pneumonia. New York, Marcel Dekker, 1994; pp. 251-265.

36. Robbins RA, Russ WD, Rasmussen JK, Clayton MM. Activation of the complement system in the adult respiratory distress syndrome. Am Rev Respir Dis 1987; 135: 651-658.

37. Langlois PF, Gawryl MS. Accentuated formation of the terminal C5b-9 complement complex in patient plasma precedes development of the adult respiratory distress syndrome. Am Rev Respir Dis 1988; 138: 368-375.

38. Weinberg PF, Matthay MA, Webster RO, Roskos KV, Goldstein IM, Murray JF. Biologically active products of complement and acute lung injury in patients with the sepsis syndrome. Am Rev Respir Dis 1984; 130: 791796.

39. Rabinovici R, Yeh CG, Hillegass LM, et al. Role of complement in endotoxin-platelet-activating factor-induced lung injury. J Immunol 1992; 149: 1744-1750.

40. Cardozo C, Edelman J, Jagirdar J, Lesser M. Lipopolysaccharide-induced pulmonary vascular sequestration of polymorphonuclear leukocytes is complement independent. Am Rev Respir Dis 1991; 144: 173-178.

41. Daniele RP, McMillan LJ, Dauber JH, Rossman MD. Immune complexes in sarcoidosis. Chest 1978; 74: 261-264.

42. Pettersen HB, Johnson E, Mollnes TE, Garred P, Hetland G, Osen SS. Quantification of nonactivated (native) complement component C9 synthesized by alveolar macrophages from patients with sarcoidosis. Scand J Immunol 1990; 3: 657-663.

43. Pettersen HB, Johnson E, Osen SS. Phagocytosis of agarose beads by receptors for C3b (CR1) and iC 3b on alveolar macrophages from patients with sarcoidosis. Scand $J$ Immunol 1990; 32: 669-677.

44. Siltzbach LE. Sarcoidosis: clinical features and management. Med Clin North Am 1967; 51: 483-502.

45. Akamine A, Raghu G, Narayanan AS. Human lung fibroblast subpopulations with different $\mathrm{Clq}$ binding and functional properties. Am J Respir Cell Mol Biol 1992; 6: 283-296.

46. O'Shea J, Brown EJ, Seligman BE, Metcalf DA, Frank MM. Evidence for distinct intracellular pools of receptors for C3b and C3bi in human neutrophils. J Immunol 1985; 134: 2580-2587.

47. Sadallah S, Lach E, Lutz HU, Schwarz S, Guerne PA, Schifferli JA. CR1, CD35 in synovial fluid from patients with inflammatory joint diseases. Arthritis Rheumatism 1997; 40: 520-526. 